\title{
RIQUEZA Y VARIEDAD DE LAS CONSTRUCCIONES AGRARIAS GALLEGAS: LOS MOLINOS DE AGUA EN EL MUNICIPIO DE BEGONTE, LUGO/ESPAÑA
}

\author{
(WEALTH AND VARIETY OF AGRARIAN CONSTRUCTIONS IN GALICIA. WATER-MILLS IN THE \\ MUNICIPALITY OF BEGONTE, LUGO/SPAIN)
}

Ignacio Cañas Guerrero, Prof. Titular de la E.T.S.I. Agrónomos de Madrid

Pedro Arias Sánchez, Prof. Titular interino de la E.I.T. Agraria y Forestal de Ponferrada

Ignacio Vicente Álvarez, Arquitecto

ESPAÑA

Fecha de recepción: 22-XПI-96

$160-11$

\begin{abstract}
RESUMEN
Durante el trabajo de investigación llevado a cabo en Galicia, en el que tratamos de analizar la integración de las construcciones agrarias en el paisaje, nos hemos encontrado con una realidad que supera, con mucho, a lo que podia uno imaginar: "los millares de construcciones populares insertadas en el paisaje". Este hecho nos complica, a la vez que nos estimula, el trabajo.

El estudio de todas y cada una de las construcciones populares de Begonte seria objeto de más de un libro. Por ello nos hemos centrado, tan sólo, en los molinos de agua, conservándose 21 construcciones en este municipio. Esto nos muestra también el enorme potencial de reutilización de construcciones agrarias que presenta Begonte. Existe, al menos, una empresa que se dedica a la reutilización de molinos de agua.
\end{abstract}

\section{SUMMARY}

During the research study carried out in Galicia in which we try to analyze the integration of the agricultural buildings in the landscape, we have found a fact that exceeds, by far, what we could imagine: "there are thousands of popular buildings inserted in the landscape". This fact complicates the work, stimulating it at the same time.

The study of all and each one of the popular buildings in. Begonte could be the subject of more than a book. That is why we have focused only on the water mills, of which there are 21 buildings preserved in this village. This also shows us the huge potential far a new use of those agricultural buildings existing in Begonte. There is one company, at least, devoted to give Begonte's water mills a new use.

\section{Introducción}

Durante el estudio de las construcciones agrarias gallegas y su integración en el medio, nos hemos encontrado con un fenómeno llamativo; el gran número de construcciones populares que están como "incrustadas" en el paisaje. Su tipología es muy variada: cruceros, "petos de animas" (monumentos que, a modo de altares de piedra, se yerguen en las encrucijadas de los caminos), hórreos, pallozas, molinos, hornos, arquitectura de ganado (cabañas, corrales, cuadras, gallineros), palomares, colmenares, pajares, bodegas, construcciones para caza y pesca (pesqueras, fosos), arquitectura del agua (fuentes, pozos), espacios feriales, herrerías, batanes, etc. Si añadimos a las cons- trucciones populares los otros elementos del patrimonio artístico: construcciones paleolíticas, dólmenes, castros, arquitectura religiosa (iglesias, capillas, ermitas), pazos, puentes, castillos, etc., podemos tener una idea de la variedad constructiva de esta comunidad autónoma.

No obstante, es necesario remarcar dos elementos que realzan esta riqueza constructiva:

$1^{\circ} \mathrm{Su}$ gran número: por ejemplo, se cita, que en una pequeña loma de San Martiño do Rosal (Pontevedra) hay 36 molinos de agua, existiendo algún municipio como Cantoira que cuenta con 64 molinos de río (Ventoso, 1996). 
$2^{\circ} \mathrm{Su}$ buen estado de conservación, que hace que en algunos casos se sigan utilizando de la misma forma que hace siglos ${ }^{1}$, comprendiéndose, así, que estudiosos de otros países se interesen por diversas construcciones gallegas $^{2}$, siendo el principal motivo de nuestro asombro y admiración.

En el presente trabajo se pretende mostrar la enorme riqueza en construcciones populares de Galicia; para ello analizamos tan sólo un municipio gallego, correspondiente a la zona Centro-Norte (Begonte) de Lugo. Y un sólo tipo de construcción, los molinos de agua de los ríos. En la actualidad, en la zona de estudio, existen 21 molinos. Se pretende, con dicho estudio, analizar tai.ıbién algunos molinos, de forma que nos ayude a conocer y conservar nuestro patrimonio arquitectónico. Ya que, aunque existen algunos estudios sobre éstos, suelen estar muy centrados en temas etnográficos, evocando, en algunos casos, unos recuerdos con tintes nostálgicos: "Foron.. pero xa non serven, pois ficaron decadentes, inutis, afastados...Agora decateime que pasaron moitos anos e que o mundo mundou máis depresa ca mín. Por fortuna, de vez en cando, algúns podemos aínda soñar sen nos preocupar en absoluto de canto valen as horas baldeiras que nos permitirán despois encher de ilusións as nosas vidas" ( Prólogo de D. Estanislao Fernández de la Cigoña Núñez, al libro de D. Andrés Sampedro).

\section{El molino y su entorno}

Siguiendo a Pallaruelo, 1994, podemos decir que "un molino es un edificio con unos artefactos que sirven para moler, estrujar, enfurtir o laminar. Pero es también el lugar donde vive y trabaja un molinero. Es una fuente de riqueza. Ha sido un elemento de dominio y de coacción. También un espejo donde se han reflejado los cambios tecnológicos y sociales que la evolución histórica ha ido trayendo".

Los molinos ocuparon un puesto fundamental en la economía de muchos pueblos, pues el pan era un elemento principal en la dieta y para ello necesitaban el molino, constituyendo, también, el lugar y objeto del folklore, que alcanzó gran riqueza, como lo expresa la cantiga de José Luis Reza Cabano ( Sampedro A., 1990):

No muíno fan cantigas,
no muíño fan concellos,
no muíno fanse amores,
e contan contos os vellos.

Se ha llegado a decir que "fueron los molinos los que hicieron de Galicia una tierra con identidad propia"3 o expresando en frase de Filgueira Valverde: "atopar un muíno é un achegamento moi fondo ó espiritu do pobo" (Ventoso, 1996). Parece claro, pues, que el molino es uno de los elementos más característicos del patrimonio etnográfico de Galicia. De ahí quizá que la práctica totalidad de los estudios de los molinos gallegos se hayan centrado en este enfoque.

Desde el punto de vista paisajístico los molinos suelen constituir hitos, con su caz, su azud, el arbolado de ribera y la edificación aneja.

\section{Tipos de molinos}

Podemos clasificar los molinos atendiendo a distintas consideraciones, tales como:

\section{Por su finalidad}

Es decir, por lo que muelen. Los principales tipos son:

1.1 Molinos de cereales

1.2 Molinos de aceite

1.3 Molinos traperos o batanes

1.4 Molinos de papel

1.5 Molinos de yeso

1.6 Molinos de vidrio

\section{Por la propiedad}

2.1 Comunales

\subsection{Privados:}

2.2.1 Familiares, autoabastecimiento para una familia

2.2.2 Profesionales, muele para fuera, mediante un cobro

\section{Por la fuerza motriz}

Puede ser de mano, de agua, de viento o con animales. Dentro de los de agua podemos distinguir de mar o de río. En estos últimos nos centraremos, distinguiendo los siguientes:

- Según que el flujo de agua sea constante durante todo el año o no.

\footnotetext{
${ }^{1}$ Parece un hecho muy llamativo que en España, en el año 1996, funcionen molinos de agua con su muñeiro. Así, Severino Pallaruelo acaba su libro: Los molinos del Alto Aragón", después de analizar cientos de molinos (sólo en molinos harineroshidráulicos se localizan 241 que existían en 1094), con el siguiente párrafo: "Hoy todas las muelas de los molinos del Alto Aragón están calladas. Algunas permanecen bajo sus guardapolvos, otras están cubiertas de polvo y telarañas, muchas duermen -para siempre- bajo los escombros".

${ }^{2}$ Como ejemplo puede verse "Estudio sobre las pallozas de la Sierra de los Ancares/España". Tesis leída en París por González F. (20-10-86) en la Sorbona y el artículo, con el mismo título, de González, F.; Peyrégne, M. y Serrano, M.: Informes de la Construcción, Vol. 39, n 392, noviembre/diciembre 1987.
} 
- Por el tipo de rueda y llegada del agua.

- Por las características constructivas de los edificios.

\section{Objetivos y zona de estudio}

Los objetivos perseguidos en este estudio son, el conocimiento de la arquitectura y las soluciones tecnológicas tradicionales, así como el estado de conservación actual de las muestras (claramente inmersas en un proceso de deterioro progresivo). Y, sobre todo, mostrar la enorme riqueza constructiva que está oculta en algunos de los municipios gallegos. No trataremos en el presente artículo delas características dela industria molinera, ya que hay abundante bibliografia al respecto.

A la hora de determinar la zona de estudio se eligió, como unidad geográfica, un municipio, estando situado éste en la zona Centro Norte de la Comunidad Gallega, concretamente el "Concello de Begonte", localizado en la Comarca Natural de "Terra Cha" y en la provincia de Lugo. La "Terra Cha" es una altiplanicie de una extensión aproximada de 208.252 Ha, que queda enmarcada al Sur de la Mariña Lucense.

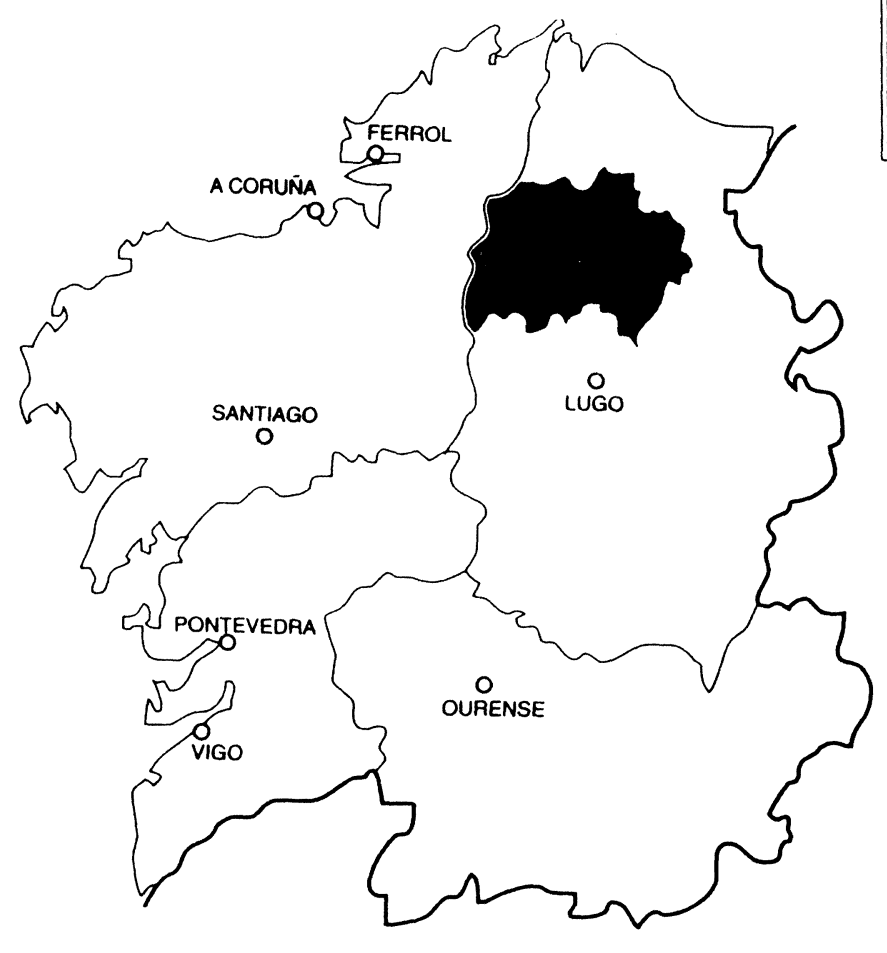

Situación de Terra Cha, dentro de Lugo.

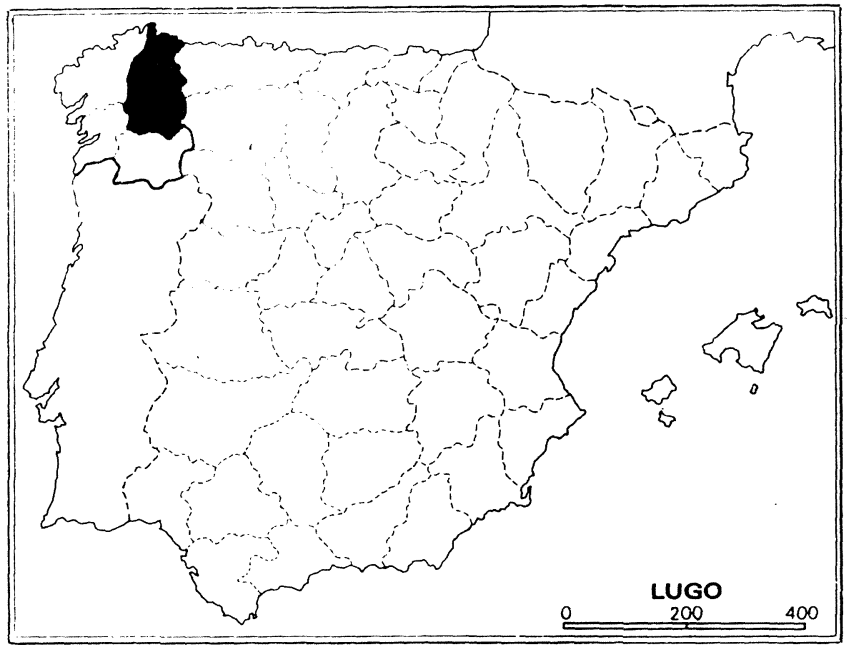

Situación de Lugo.

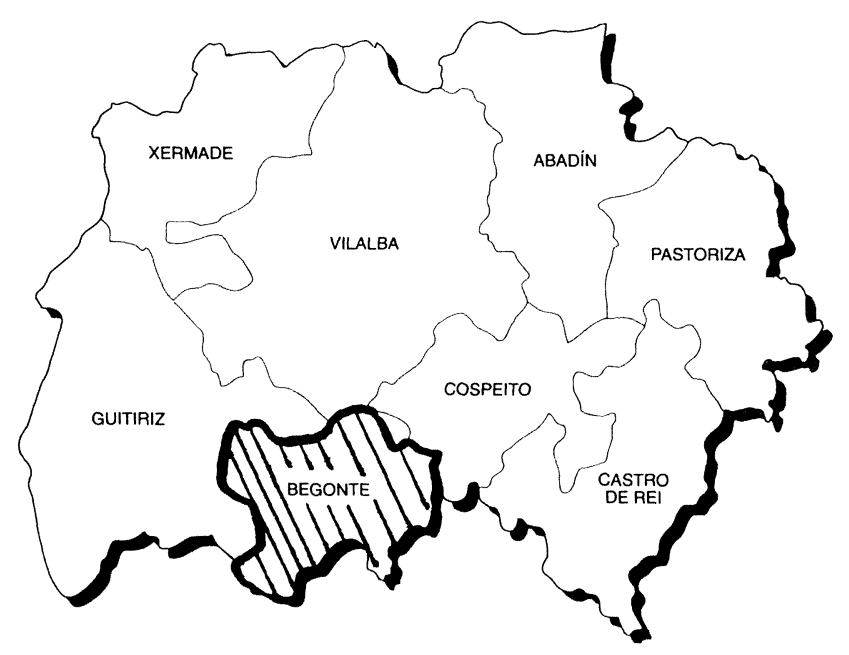

Situación de Begonte, dentro de la comarca de Terra Cha.

Situación de la zona de estudio.

\footnotetext{
${ }^{3}$ Contraportada del libro de D. Andrés Sampedro.
} 
Dentro de la gran extensión de "Terra Cha", comprende en la actualidad diezmunicipios: Abadín, Begonte, Castro de Rei, Cospeito, Guitiriz, Muras, Pastoriza, Pol, Vilalba y Xermade. Al Sur de esta gran extensión geográfica y ocupando la parte central de la misma, está enclavado el Municipio de Begonte, cuyos límites son: por el Norte los municipios de Vilalba y Guitiriz, al Este los de Cospeito y Rábade, al Sur el de Otero de Rei y al Oeste los de Friol y Guitiriz. La extensión del municipio es de $127 \mathrm{~km}^{2}$, repartidos en un terreno generalmente montañoso, si bien las alturas no son muy pronunciadas, no sobrepasando los $750 \mathrm{~m}$ en ningún caso. Las mayores elevaciones están hacia el Sur, donde se alcanzan los $741 \mathrm{~m}$, para descender, un poco más al Norte, en las proximidades del río Ladra y Parga, hasta los $400 \mathrm{~m}$, siendo éstas las zonas con menor altitud del municipio.

En todo el municipio se encuentra el agua en abundancia, lo que va a afectar, de forma determinante, el desarrollo del trabajo (al igual que en tiempos pretéritos condicionó el desarrollo de la comarca y de la vida de sus habitantes), ya que los molinos encontrados son hidráulicos y se han utilizado para moler grano. La importancia que pudieron tener los molinos en el pasado, no sólo viene dada por la mayor o menor presencia de cursos fluviales en los que construir las edificaciones, sino que también vendrá condicionada por la demanda existente entre la población de los servicios que estas industrias de molienda prestaban. Un dato que puede ayudarnos a comprender este hecho, es el siguiente: del total de la superficie municipal, unas $12.700 \mathrm{Ha}$, un porcentaje aproximado del $20,8 \%$ puede considerarse como superficie dedicada al cultivo de cereal (trigo, avena, centeno y maíz, principalmente), según datos consultados en la Cámara Agraria Local, y en los que se observa un claro y progresivo descenso de este porcentaje con el paso de los años. Por lo que al hacer un simple cálculo y multiplicar esta superficie, por unas producciones medias anuales entre $1.400-1.500 \mathrm{~kg} / \mathrm{Ha}$ (la aptitud del medio, suelo y clima, para el cultivo del cereal, puede considerarse como buena), obtenemos la producción municipal aproximada (alrededor de las $4.000 \mathrm{t}$ ), teniendo en cuenta que las economías de la época eran de subsistencia y con la mayoría de la producción dedicada al autoconsumo (de los propios habitantes, o del ganado que estos poseían), siendo los molinos la única industria capaz de transformar ese cereal, es fácil imaginar la carga de trabajo que podían tener, así como la labor esencial que éstos prestaban en la sociedad.

\section{Metodología}

La metodología de trabajo que se ha seguido se centró, principalmente, en una labor de campo, basándonos en informadores locales, debido a la ausencia de bibliografia específica de la zona. Se eligieron personas que tuvieran una relación directa con los molinos (propietarios, herederos, familiares, etc.), o en su defecto, que fueran usua- rios del molino o conocieran la historia de éste. Durante las entrevistas se intentó recoger el mayor número de datos posible, en aspectos tales como: localización, accesos y denominación del molino; estado actual de conservación general y de los distintos elementos que lo conforman; propietarios actuales y pasados (fecha de construcción, de abandono de la actividad y causas de éste, existencia de documentación, etc.); consideraciones sobre su construcción, características constructivas y mecánicas (materiales, formas de uso, procedencia, etc.). Como ejemplo anecdótico citaremos el caso de una persona de 96 años, D. Jesús Morandeira Yáñez que, con una memoria prodigiosa, fue capaz, él solo, de citar y localizar sobre el terreno, exactamente, un número de 17 molinos, del total de los 21 presentes en el municipio, además de aportar otra serie de datos sobre éstos de gran interés.

Una vez finalizada esta fase se procedió a la elaboración del mapa de distribución de los molinos, completado y corregido definitivamente en la fase del trabajo de campo, donde se finalizó la toma de datos definitiva de todas las construcciones. Los resultados obtenidos se exponen a continuación.

La localización de los molinos, en los cursos fluviales del municipio, fue la siguiente:

Río Ladra, en éste se localizan: "Muíno da Caseira de Carballido", "Muíño de Carral", "Muíño de Redondo".

Río Parga, donde se localizan, "Muíño de Cagiao", "Muíño de Blanco", "Muíño de Fontechousa o de Luciano".

Sobre otros cursos de agua de menor importancia:

Rego Portolousado, localizándose: "Muíño de Magín", "Muíño da Vila", "Muíño do Pozo Mouro", "Muíño do Rato".

Rego Xabarixo: "Muíño de Portaferreira o de Valerio", "Muíño de Cristobo da Pena", "Muíño de Barra".

Rego de Portamelle: "Muíño do Tío María", "Muíno de Aloarriba".

\section{Rego da Lama: "Muíño de Daniel".}

Rego do Peto: "Muíño de Pichin", "Muíño de Casanova".

Rego de Illan: "Muíño de Riocaldo".

Rego do Medo: "Muíño de Paulo".

Lagoas do Ollo: "Muíño do Ollo".

Posteriormente, en cada molino se procedió a la toma de datos directa en la propia construcción, siendo éstos: 


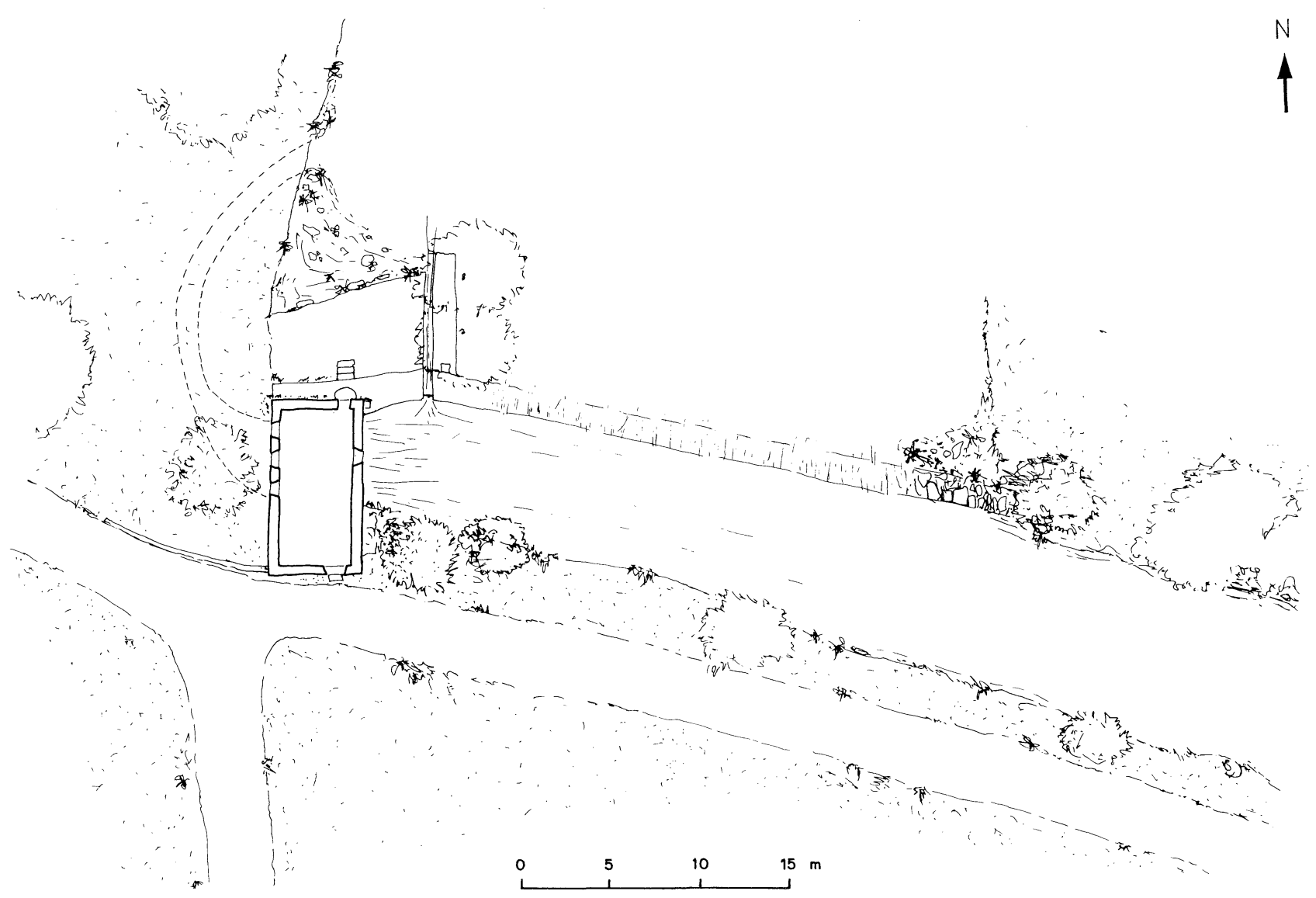

Planta general y posición con relación al cauce fluvial del Muiño de Cagigao. Molino con presa que se levanta sobre el lecho fluvial del río Parga. La presa actual fue remodelada a partir de la presa antigua, a raiz del establecimiento del Club Fluvial de Baamonde.

\section{- En la edificación}

Alzados, perfiles, distribución en planta, cortes y secciones interiores, elementos constructivos como puertas, ventanas y escaleras, partes de la cubierta (vigas, cerchas, etc.), entradas y salidas de agua, características de los cubos $\mathrm{y}$, en general, cualquier detalle o elemento constructivo considerado de interés.

- En los elementos mecánicos

Compuertas de entrada de agua, rodete, eje transmisor de movimientos, piedras de molienda (soportes y elementos que las contienen), depósitos de grano (dosificadores), depósitos de harina, separadores, etc.

\section{- En la presa}

Dimensiones en anchura, altura y longitud del muro, capacidad de almacenamiento de agua, compuertas y aliviaderos, medidas, materiales y funcionamiento.
Por último, el trabajo de campo concluyó con la elaboración de un reportaje fotográfico, en éste se intentó recoger, como mínimo, fotografias generales de emplazamientos de los conjuntos, de detalles de los elementos constructivos, de elementos mecánicos y accesorios, así como de las actividades en el molino.

El último paso en la metodología de trabajo a seguir, es el procesamiento de la información -previamente obtenida en las fases anteriores- y la obtención-elaboración de resultados, con el establecimiento de tipologías constructivas tradicionales, materiales usados y formas de empleo, inventario del patrimonio, etc.

\section{Resultados}

Una vezlocalizados los molinos y visitados, con la toma de datos realizada, se llevó a cabo el procesamiento de esa información, previamente recogida, con el fin de establecer unas tipologías para los molinos de la zona, bajo las cuales poder clasificarlos; estas clasificaciones de los molinos las podemos resumir: 


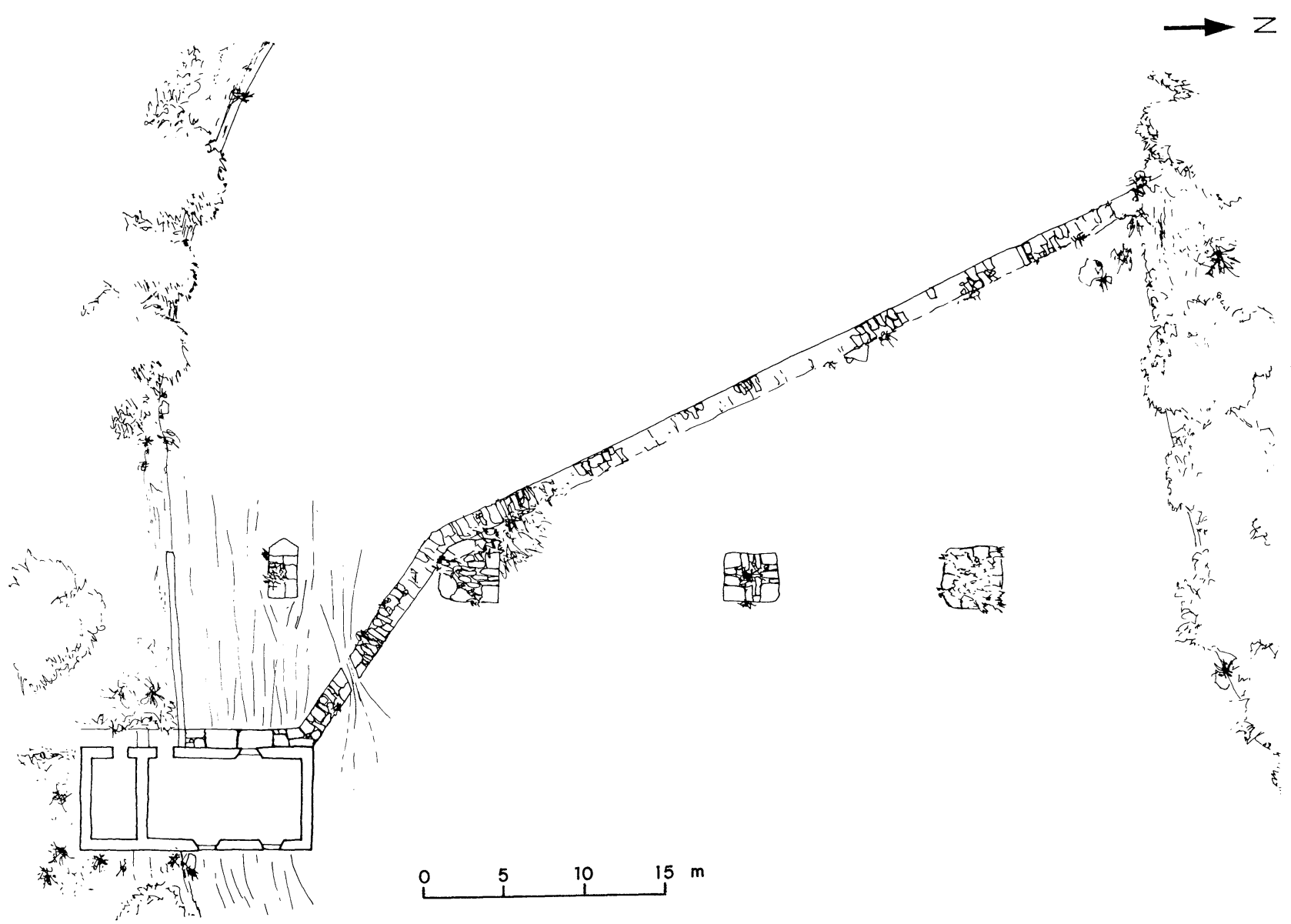

Planta general y posición con relación al cauce fluvial del Muiño de Blanco, situado en el río Parga. Molino con presa. El cuerpo central de la presa presenta, en su parte superior y en una longitud aproximada de $40 \mathrm{~m}$, un rebaje de unos $20 \mathrm{~cm}$ en su altura.

\section{Por su finalidad}

Es decir, por lo que muelen.

En este caso, todos los molinos del municipio son molinos de cereales.

\section{Por la propiedad}

\subsection{Comunales}

Algunos de los molinos anteriormente enumerados, en el pasado y principalmente en el momento de su construcción, fueron usados de un modo comunal, de forma que se repartía el uso del molino mediante unos turnos, previamente pactados de mutuo acuerdo, pero, con el paso del tiempo, esta forma de uso se fue perdiendo en todos los casos, pasando a ser considerados en los últimos tiempos como molinos privados; entre éstos podríamos citar, sin riesgo a equivocarnos, el "Muíño de Cagigao" y el "Muíño da Vila"; del resto de los molinos del municipio se tienen ciertos indicios de este hecho, pero no ha podido llegar a ser verificado.

\subsection{Privados}

Dentro de esta tipología, cabría distinguir:

\subsubsection{Familiares}

En este caso el uso era únicamente individual, no trabajando para el resto de la población que demandara sus servicios; este hecho se produciría, bien por no verse sometidos a la carga fiscal, vía impuestos que esto supondría, o por no disponer de la mano de obra necesaria para atender esta industria. Aquí podremos incluir, el "Muíño do Ollo" y "Muíño de Daniel" (éste funcionó bajo este régimen en los últimos años, anteriormente se podría considerar como molino profesional)

\subsubsection{Profesionales}

Entre éstos se considera a los molinos que trabajan de cara al público y con ánimo de lucro, para lo cual debían de tener una serie de permisos en regla y pagar los correspondientes impuestos. El resto de los estudiados son de este tipo: "Muíño da Caseira de Carballido", "Muíño de Carral", "Muíño de Redondo", "Muíño deCagigao", "Múíno 


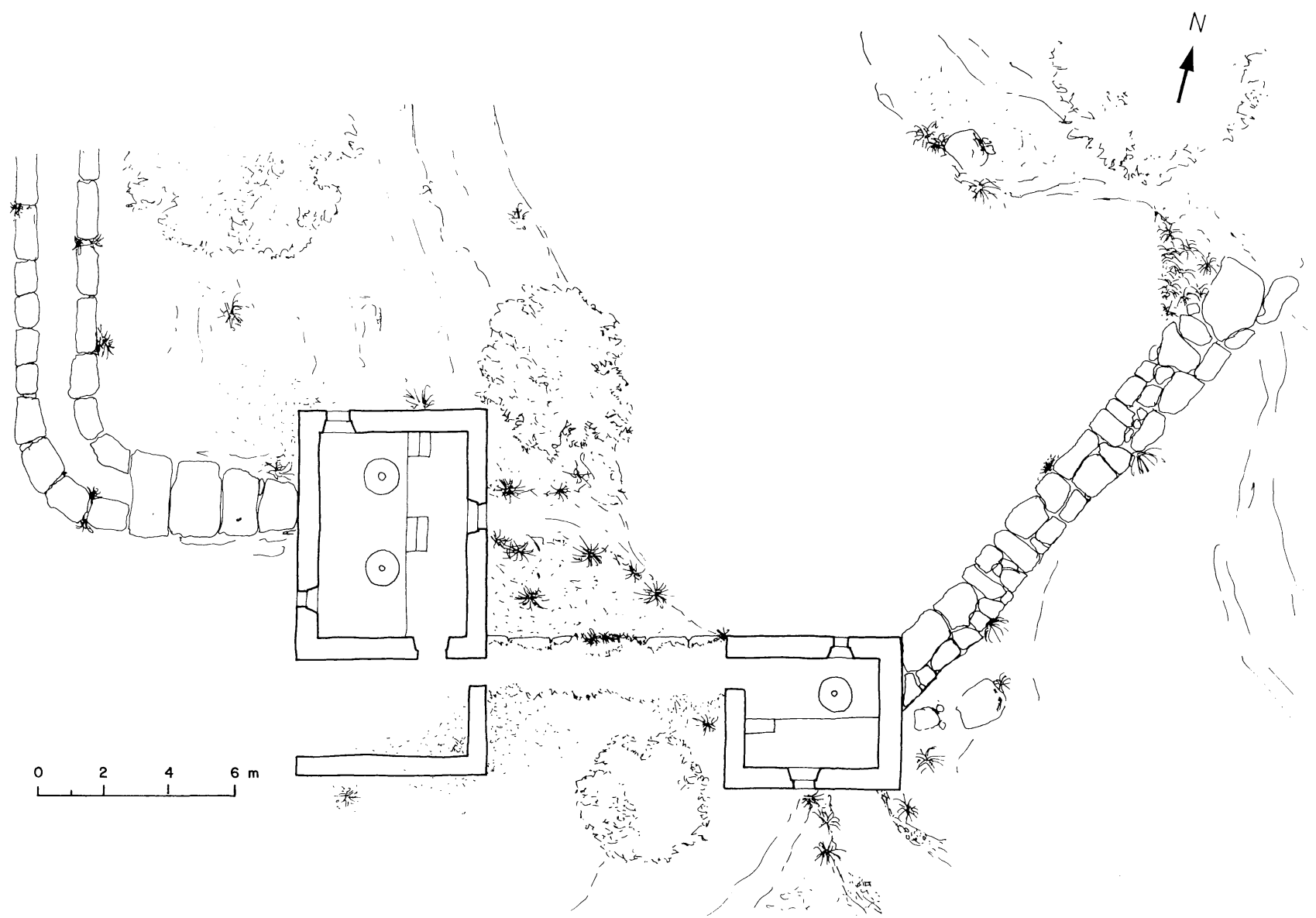

Planta general y posición con relación al cauce fluvial del Muiño de Portaferreira. Se aprovecha el agua para mover dos molinos: el primero, con dos ruedas y el segundo, con una. Situados en el Rego Xabarixo.

de Blanco", "Muíño de Fontechousa o de Luciano", "Muíño de Magín", "Muíño do Pozo Mouro", "Muíño do Rato", "Muíño de Portaferreira o de Valerio", "Muíño de Cristobo da Pena", "Muíño de Barra", "Muíño do Tio Maria", "Muíño de Aloarriba", "Muíño de Pichin", "Muíño de Casanova", "Muíño de Riocaldo", "Muíño de Paulo".

\section{Por la fuerza motriz}

Todos los molinos del municipio son molinos de agua de río. Dentro de esta tipología, estableceremos una subdivisión:

- Según que el flujo de agua sea constante durante todo el año o no.

\subsection{Molinos de agua de río}

Considerando aquí los ríos que mantienen su caudal todo el año, no secando en ninguna época, estarían englobados los siguientes: "Muíño da Caseira de Carballido", "Muíño de Carral", "Muíño de Redondo", "Muíño de Cagiao",
"Muíño de Blanco", "Muíño de Fontechousa o de Luciano".

\subsection{Molinos de agua de regato}

Considerando aquí los ríos que presentan grandes oscilaciones de su caudal a lo largo del año, surgiendo una época en la cual el caudal seca casi todos los años, se englobarían los siguientes: "Muíño de Magín", "Muíño da Vila", "Muíño do Pozo Mouro", "Muíño do Rato", "Muíño de Portaferreira o de Valerio", "Muíño de Cristobo da Pena", "Muíño de Barra", "Muíño do Tío María", "Muíno de Aloarriba", "Muíño de Daniel", "Muíño de Pichin", "Muíño de Casanova", "Muíño de Riocaldo", "Muíño de Paulo", "Muíño do Ollo".

- Por el tipo de rueda y llegada del agua

\subsection{Por la forma como es conducida el agua hacia el} molino

\subsubsection{Molinos con presa}

Ésta es una construcción formada a base de los materiales 


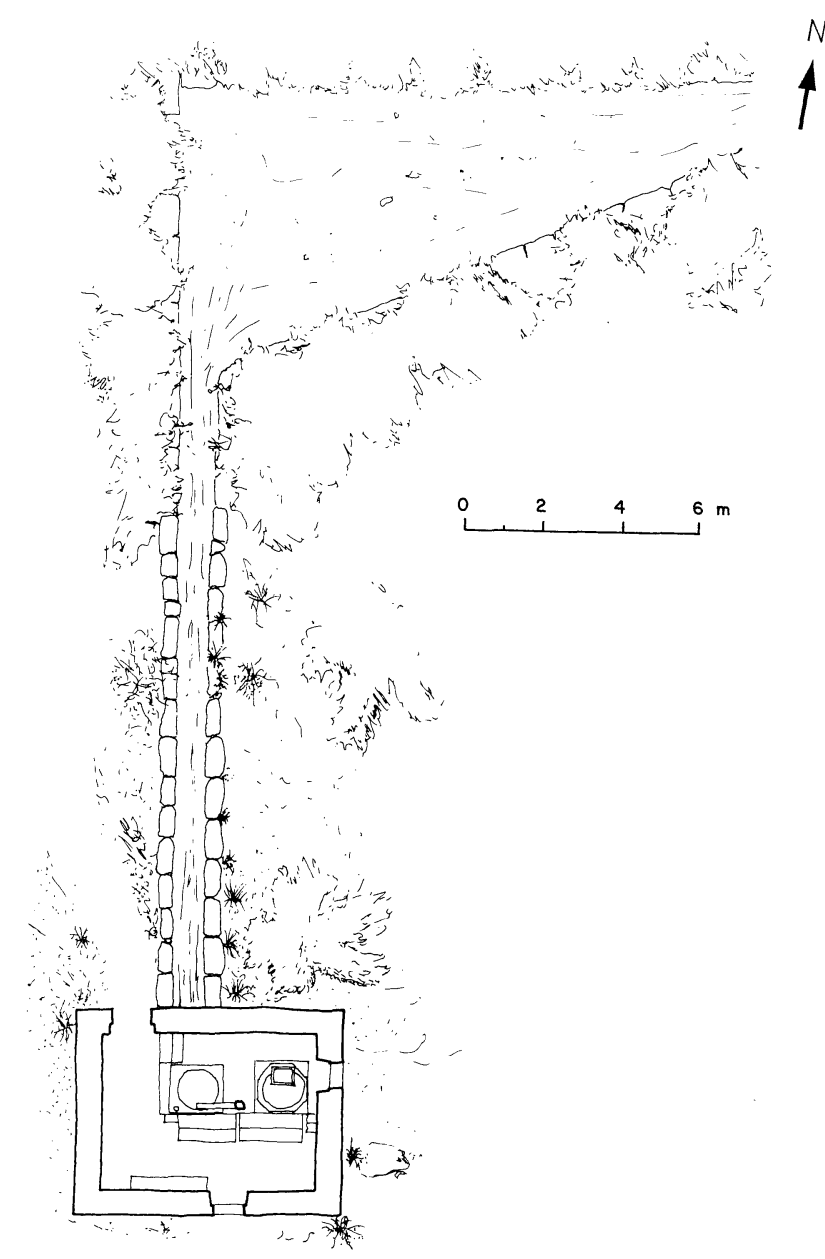

Planta general y posición con relación al cauce fluvial del Muiño de Tío Maria, pasando la totalidad del agua del Rego de Portamenelle a través del molino. de la zona (generalmente coincidentes con los del molino), que se levanta sobre el lecho fluvial de una orilla a otra del río, alterando el normal discurrir del mismo al provocar que el agua se almacene, consiguiendo, como resultado, un aumento del calado del río en este punto. Molinos con esta construcción añadida son, "Muíño da Caseira de Carballido", "Muíño de Carral", "Muíño de Redondo", "Muíño de Cagigao", "Muíño de Blanco" y "Muíño de Fontechousa o de Luciano".

3.1.2. Molinos con presa y canal de entrada, sin ninguna construcción auxiliar para almacenar el agua

Este caso se da en algunos de los molinos de agua de regato, en los que el curso fluvial es alterado mediante una presa que desvía, total o parcialmente, el cauce del río hacia un canal artificial, construido normalmente a base de grandes bloques de granito o de pizarra, que conduce el agua hacia el molino, normalmente este canal, en su último tramo presenta una gran caída o pendiente para conseguir que el agua comunique más energía a los molinos, con esta tipología, nos encontramos: el "Muíño de Magín", "Muíño da Vila", "Muíño do Pozo Mouro", "Muíño de Cristobo da Pena", "Muíño de Barra", "Muíño de Aloarriba", "Muíño de Pichin", "Muíño de Casanova" y "Muíño de Paulo".

3.1.3. Molinos con presa y canal de entrada y con una construcción anexa anterior para almacenar agua

En este caso, únicamente nos encontramos con el "Muíño do Rato"; un caso especial es el "Muíño de Portaferreira", que, debido a estar separado en dos construcciones inde-
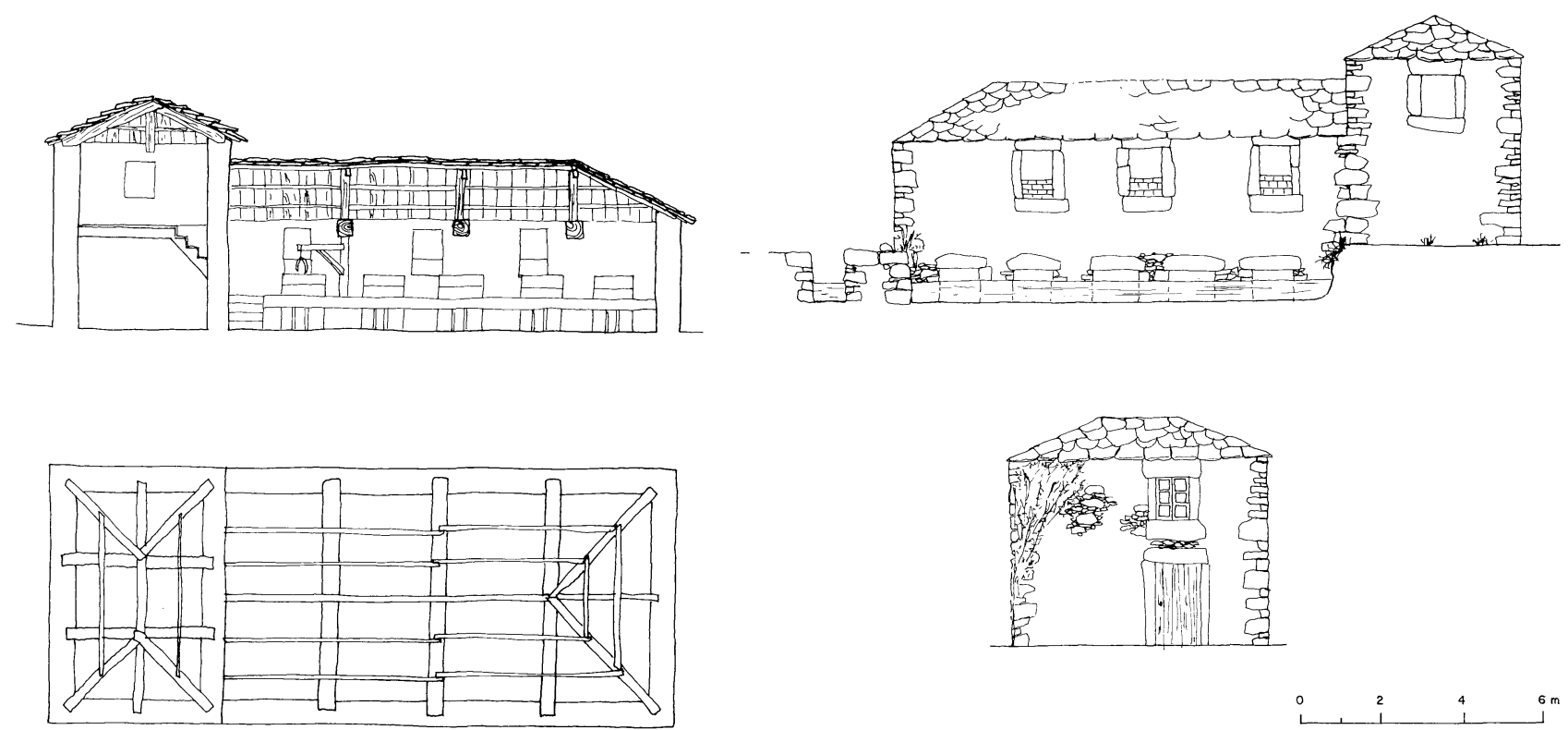

Sección, alzados y cubiertas del Muiño de Carral. Es el molino más grande del municipio de Begonte, presenta 5 muelas de moler. Está situado en el cauce del río Ladra, siendo su estado de conservación, malo. 

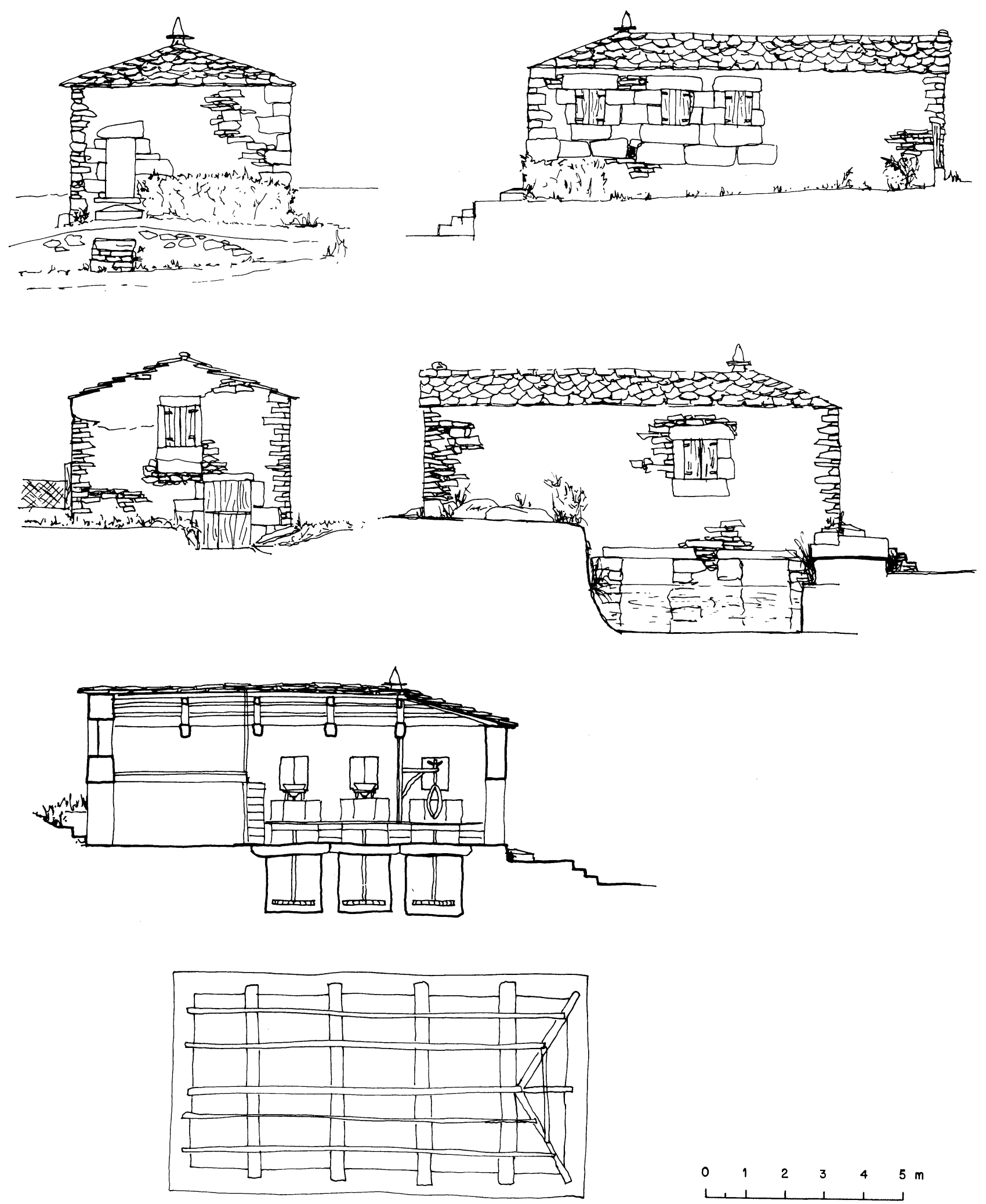

Sección, alzados y cubiertas del Muíño Cagigao. Exteriormente el molino se encuentra bastante bien conservado, con los alrededores libres de maleza, ya que se encuentra dentro de las instalaciones del Club fluvial.

(c) Consejo Superior de Investigaciones Científicas 

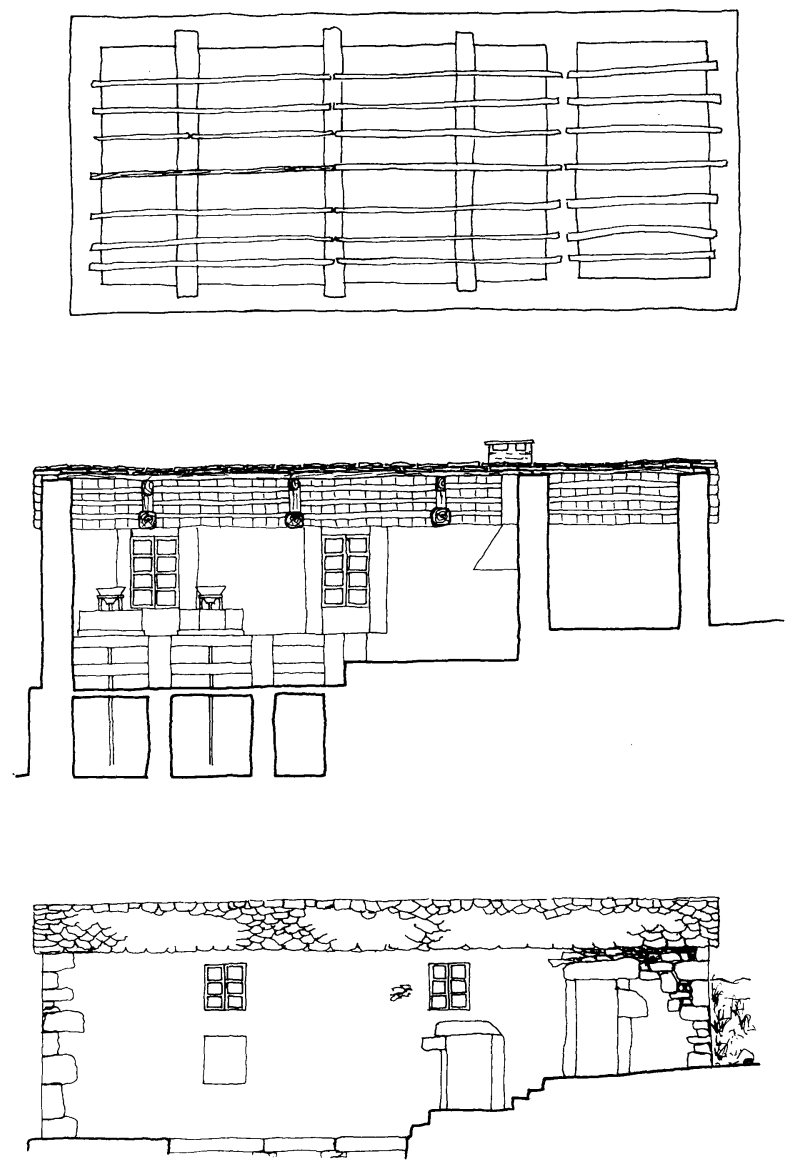

Sección, alzados y cubiertas del Muíno de Blanco. Estado de conservación: entre bueno y regular.
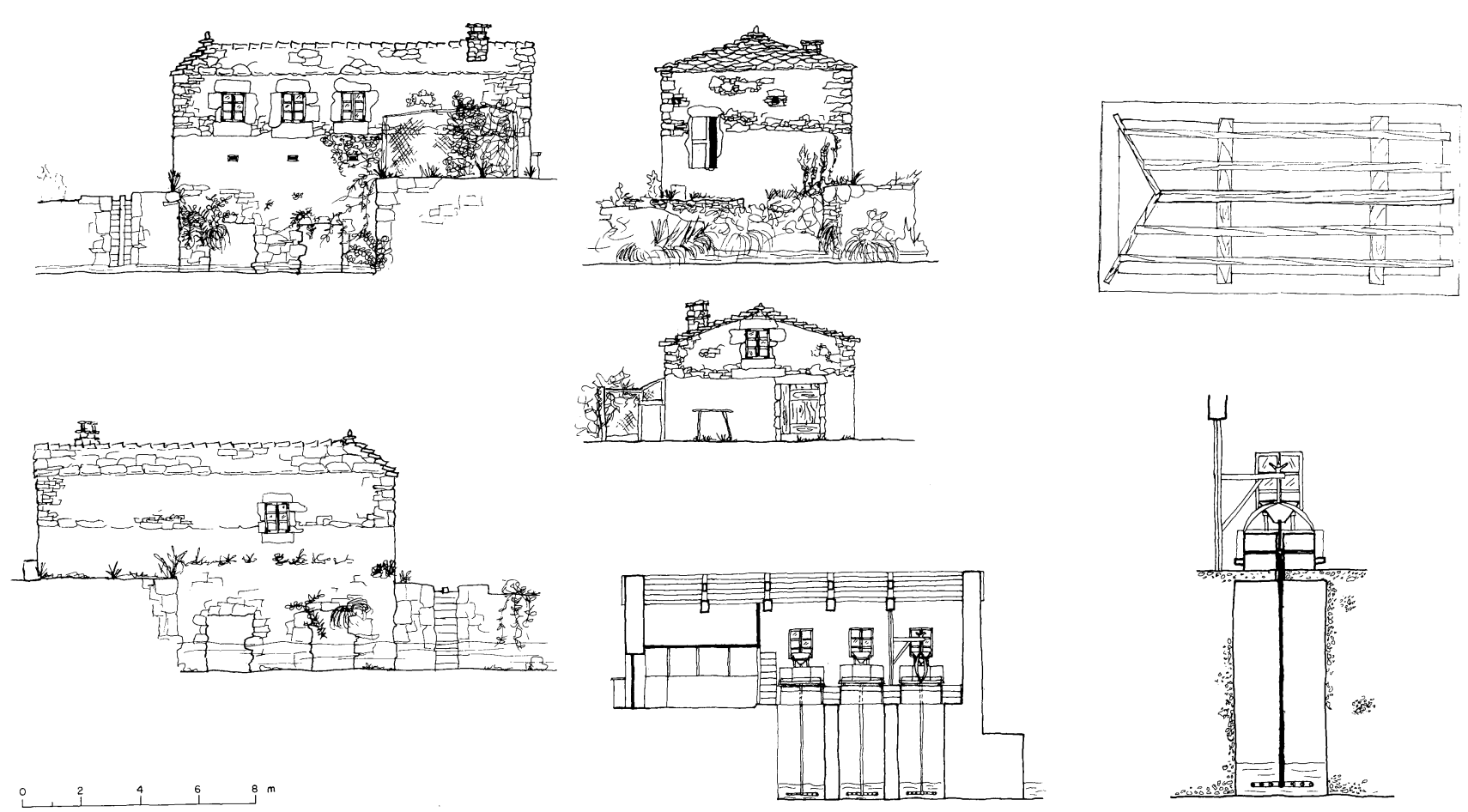

Sección, alzados y cubiertas del Muiño de Fontechousa. Estado de conservación: muy bueno; actualmente se sigue utilizando como molino. 

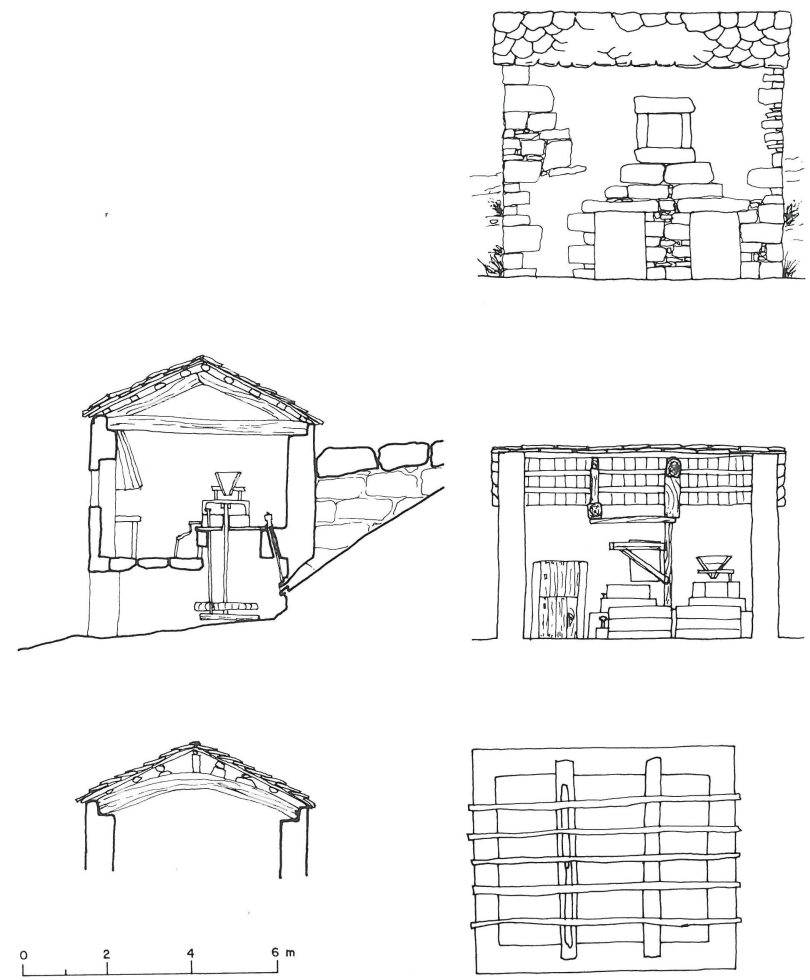

pendientes pero contiguas, en la primera de ellas el agua entra vía presa y canal, y en la siguiente, el primer agua, es aprovechada mediante una presa anexa a la construcción.

\subsubsection{Molinos situados sobre el curso fluvial sin ninguna construcción anexa}

En este caso, el molino aprovecha directamente la energía del agua, sin ningún tipo de construcción auxiliar, situándose directamente sobre el curso fluvial; encontramos los siguientes: "Muíño de Riocaldo" y "Muíño do Ollo".

\subsubsection{Molinos situados sobre el curso fluvial y con una construcción anexa anterior para almacenar agua}

En dos casos, y debido a quela cantidad de agua que circula por el curso fluvial es escasa, para aumentar el caudal que llega al molino se construyó una balsa o alberca donde el agua era acumulada, hasta que el volumen de ésta era suficiente para mover las ruedas del molino; esta balsa suele ser construida aprovechando las condiciones naturales del terreno, en este caso, tenemos: el "Muíño de Daniel" y "Muíño de Tío María".

Sección, alzados y cubiertas del Muiño de Tío María. Estado de conservación: regular.

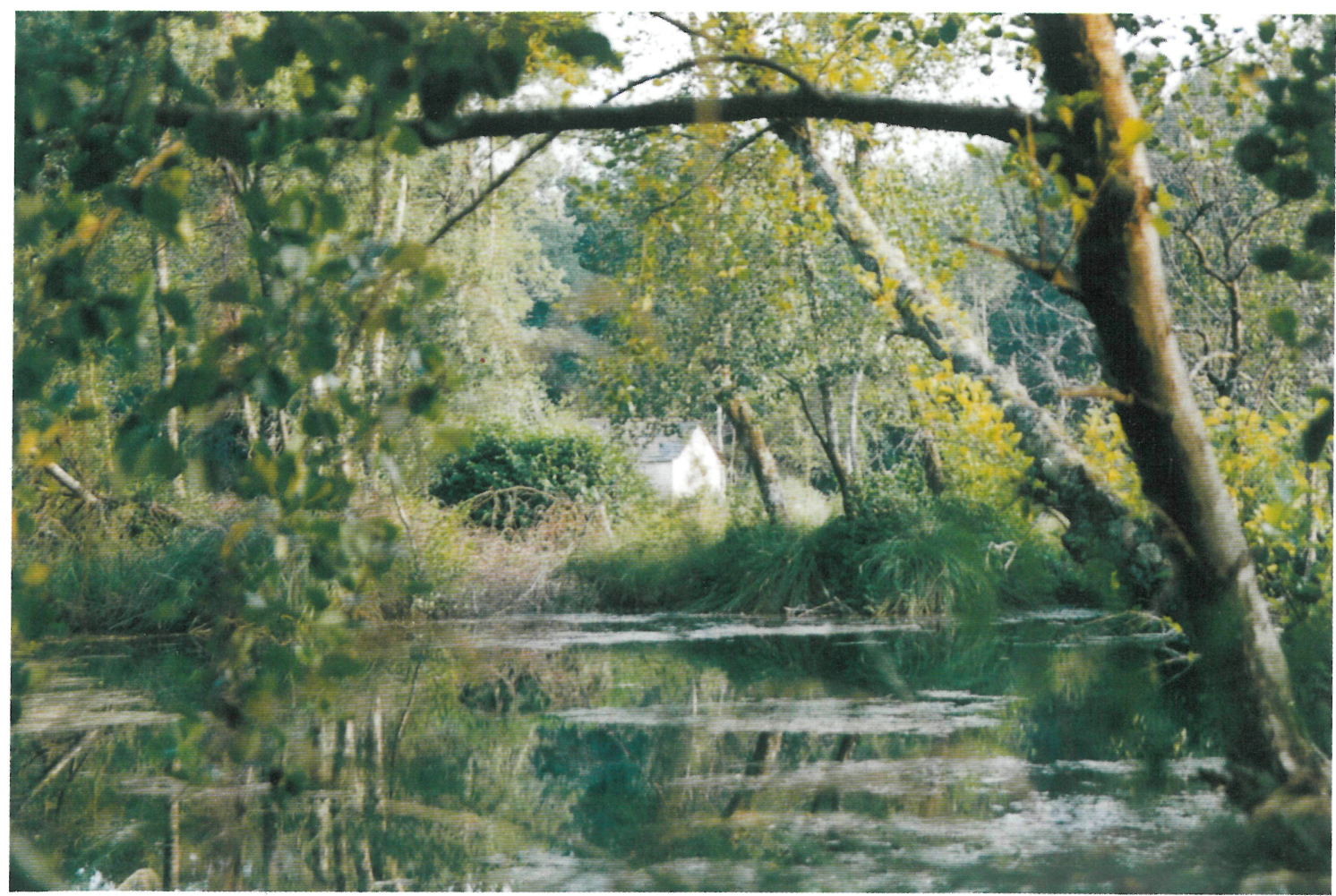

Muíño do Ollo. En primertérmino, "Pozo pequeño do Ollo"; nacimiento del agua que aprovecha el molino. Al fondo, el molino. Molino con una única muela. 


\subsection{Según el número de ruedas que presenta cada molino}

\subsubsection{Molinos de una única rueda de moler}

"Muíño do Pozo Mouro", "Muíño de Aloarriba", "Muíño de Paulo", "Muíño do Ollo". Segundo "Muíño de Portaferreira".

\subsubsection{Molinos con dos ruedas de moler}

"Muíño da Caseira de Carballido", "Muíño de Redondo", "Muíño de Magín", "Muíño do Rato", "Muíño de Cristobo da Pena", "Muíño de Barra", "Muíño do Tío María", "Muíño de Daniel", "Muíño de Pichín" "Muíño de Casanova", "Muíño de Riocaldo". Primer "Muíño de Portaferreira".

\subsubsection{Molinos con tres ruedas de moler}

"Muíño de Cagiao", "Muíño de Blanco", "Muíño de Fontechousa o de Luciano",

\subsubsection{Molinos con cinco ruedas de moler}

"Muíño de Carral".

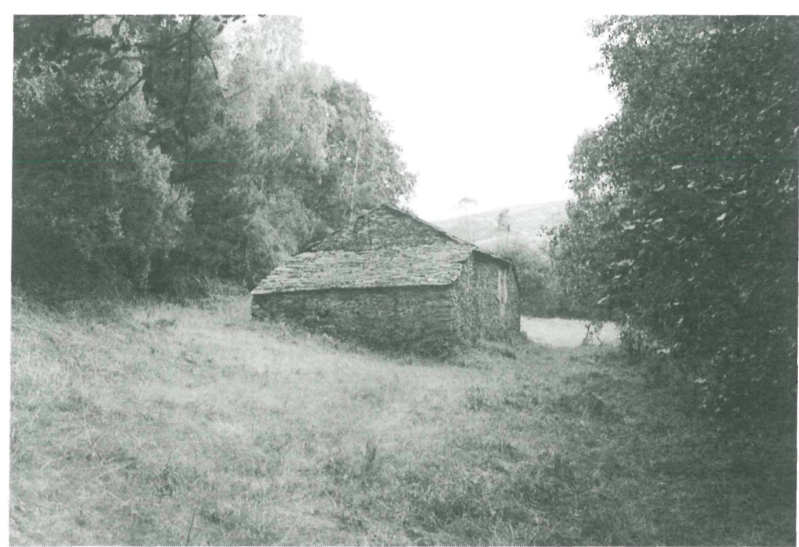

Muiño de Magín. Molino con presa y canal de entrada. Molino con dos ruedas.

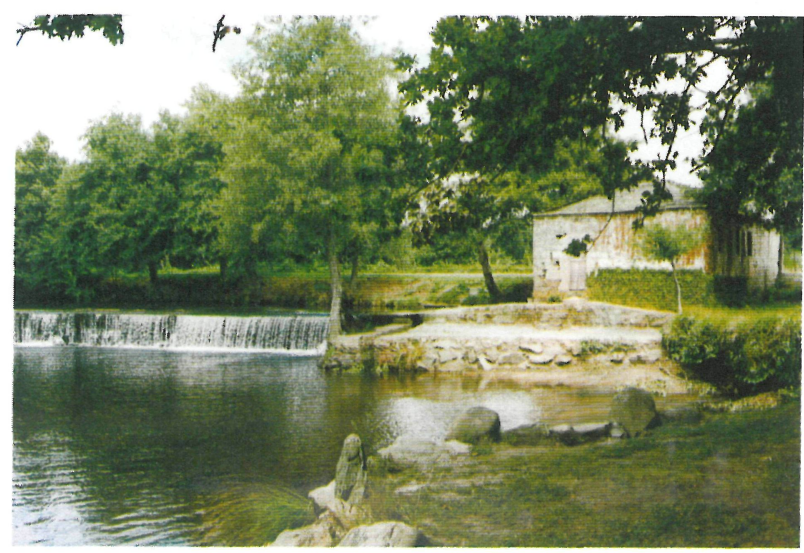

Muíño de Cagigao. Molino con presa. Molino con tres ruedas.

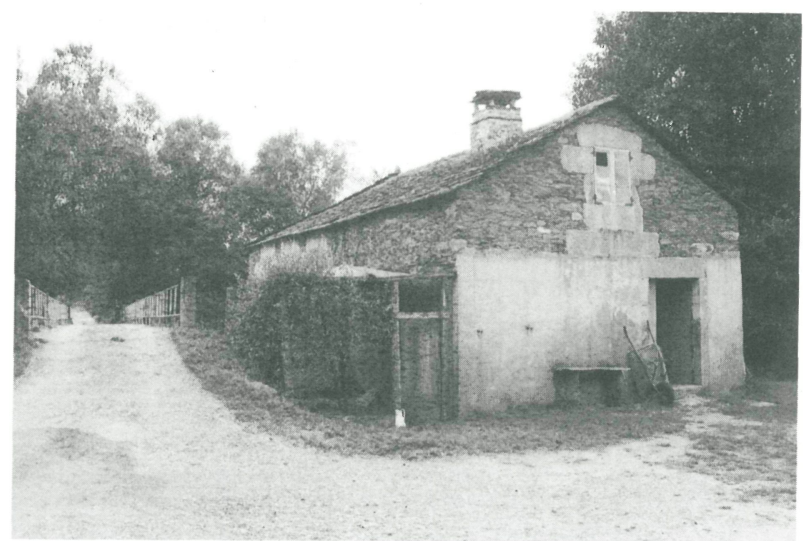

Muiño de Fontechousa. Actualmente, funcionando como molino. 1/olno con tres ruedas.

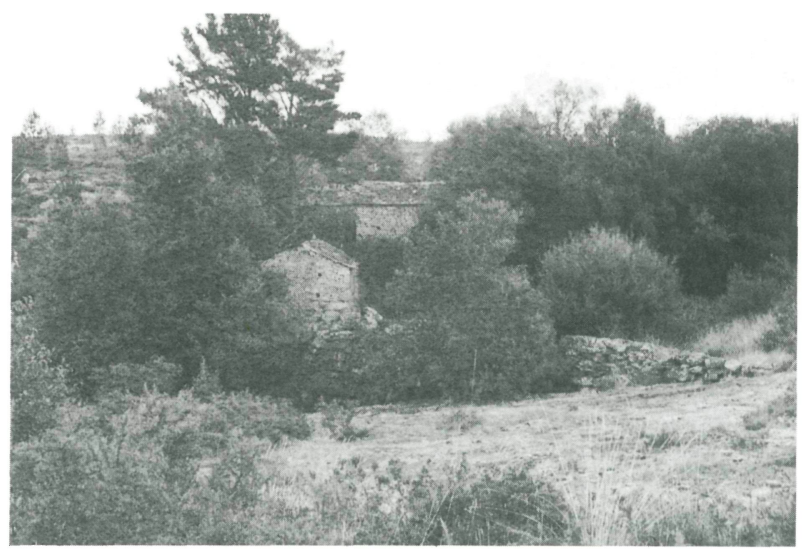

Muiño de Portaferreira (conjunto). El agua del primer molino, alime'nu al segundo.

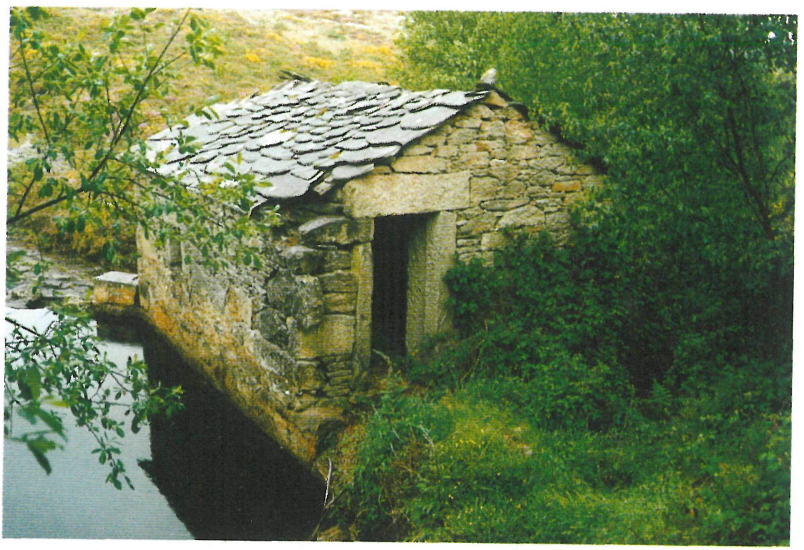

Muiño de Pontaferreira, detalle del último molino.

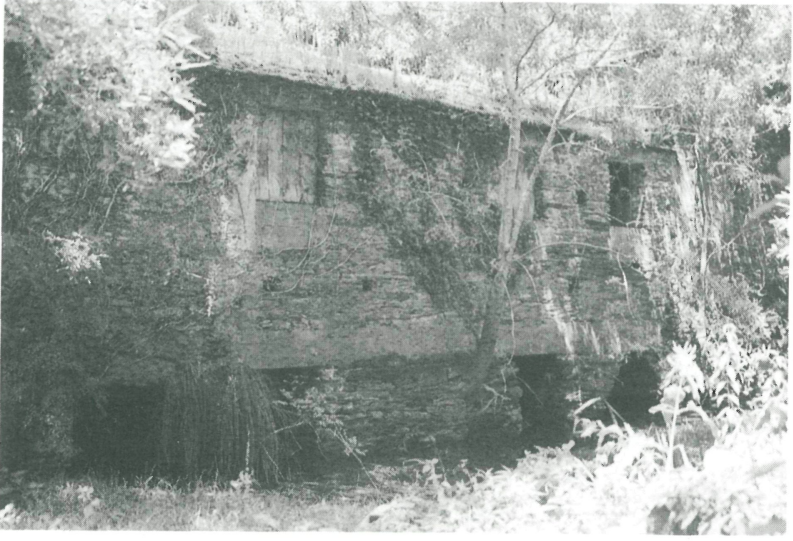

Muiño de ('arral. Molino con cinco ruedas.

(c) Consejo Superior de Investigaciones Científicas 


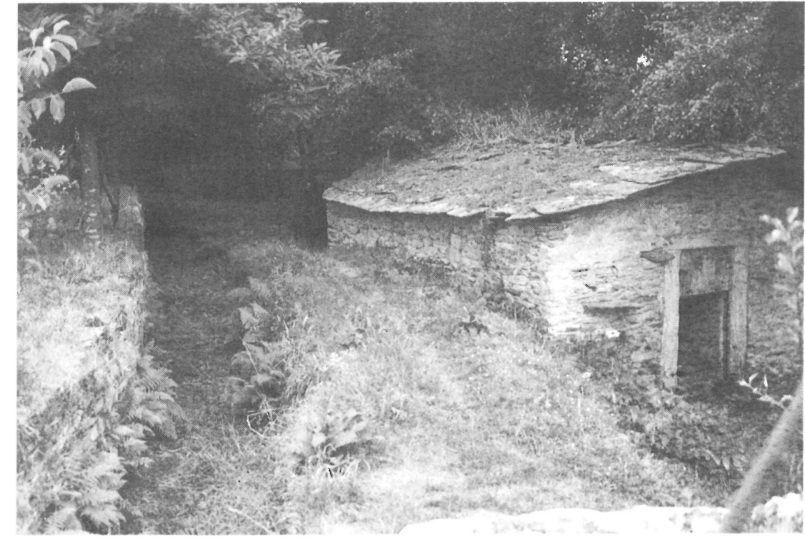

Muiño de Pozo Mouro

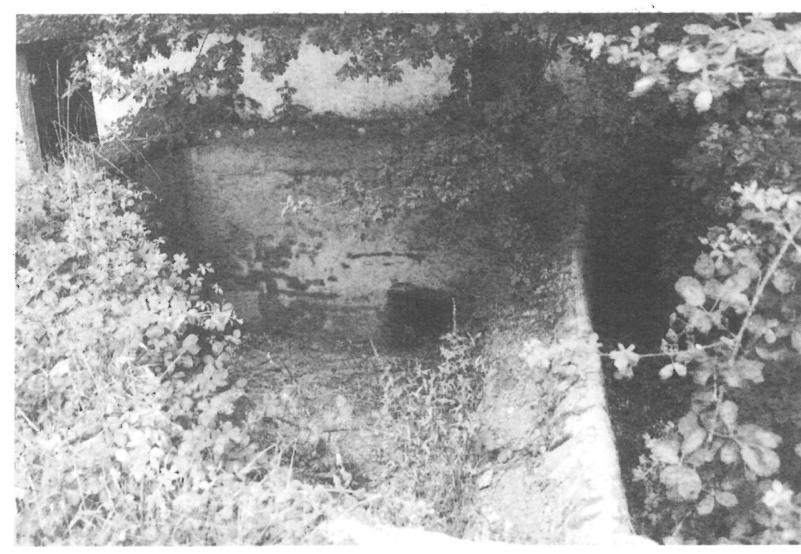

Detalle del canal de entrada y alberca del Muíño de Rato.

- Por las características constructivas de los edificios, haremos la clasificación tipológica teniendo en cuenta

\subsection{Cubiertas}

Las clasificaremos por:

\subsubsection{Forma}

Las cubiertas de los molinos estudiados son, fundamentalmente, cubiertas a cuatro aguas, encontrándonos algunas raras excepciones a dos y a tres aguas.

\subsubsection{Estructura}

Las estructuras de soporte encontradas fueron casi siempre cerchas, siendo las excepciones mínimas, como en el caso del "Muíño do Tío María", en el que nos encontramos, aparte de una cercha, una viga con forma de arco, como estructura de soporte de la cubierta.

\subsubsection{Materiales}

Encontramos los utilizados en las cubiertas, como estructura de soporte, formando las cerchas, en todos los casos de madera, principalmente de castaño. Como elemento de cobertura se utilizan las pizarras poco elaboradas, de gran tamaño y elevado grosor y peso.

\subsection{Fachadas}

\subsubsection{Materiales utilizados}

Todas las construcciones estudiadas presentan una gran similitud en cuanto a los materiales utilizados, coincidentes, en todos los casos, con los presentes de forma natural en la zona. Así, para la construcción de muros fueron utilizados materiales metamórficos, principalmente pizarras y esquistos, en todos los molinos estudiados, excepto en los molinos siguientes: "Muíño de Daniel", "Muíño do Tío María", "Muíño de Aloarriba", "Muíño de Barra", "Muíño de Cristobo da Pena" y "Muíño de Portaferreira o de Valerio", en los cuales, los muros, están construidos a base de bloques de granito, más o menos grandes y regulares.

\subsubsection{Revocos}

En la mayoría de los casos los muros se encuentran sin ningún tipo de revoco, alguna vez se ha utilizado el mortero de cal.

\subsection{Estructura vertical}

El sistema constructivo está formado por muros de carga en todos los casos, excepto en el "Muíño do Ollo", ya que debido a una remodelación que sufrió el molino, mediante la cual se subió la cubierta en altura, la porción de muro exterior nuevo se realizó a base de tabique de ladrillo simple y como estructura de soporte pequeños pilares de hormigón, descansando sobre los muros de carga primitivos. El grosor normal de los muros de carga varía entre los $60 \mathrm{~cm}$ y los $80 \mathrm{~cm}$.

\subsection{Carpintería}

Los materiales usados, tanto en puertas como en ventanas, son madera de castaño, utilizándose como dinteles, jambas $\mathrm{y}$ antepechos de puertas y ventanas, bloques de granito.

\subsection{Número de plantas que presenta o presentaba ori- ginalmente la construcción}

\subsubsection{Dos plantas}

"Muíño da Caseira de Carballido", "Muíño de Carral", "Muíño de Redondo", "Muíño de Cagiao", "Muíño de Blanco" "Muíño de Fontechousa o de Luciano"y "Muíño de Riocaldo".

\subsubsection{Una planta}

"Muíño de Magín", "Muíño do Pozo Mouro", "Muíño do Rato", "Muíño de Portaferreira o de Valerio", "Muíño de Cristobo da Pena", "Muíño de Barra", "Muíño do Tío María", "Muíño de Aloarriba", "Muíño de Daniel", "Muíño de Pichin", "Muíño de Casanova", "Muíño de 
Riocaldo", "Muíño de Paulo", "Muíño do Ollo" y "Muíño da Vila".

\subsection{Existencia de edificación anexa al cuerpo central del molino}

A estas edificaciones se le dan los usos más diversos, entre otros: alojamiento del ganado ("Muíño de Carral", "Muíño de Blanco", "Muíño de Fontechousa", "Muíño de Cristobo da Pena"); como almacén de grano o de herramientas ("Muíño de Carral", "Muíño de Redondo", "Muíño de Cagiao", "Muíño de Blanco", "Muíño de Fontechousa" y. "Muíño de Riocaldo"; como vivienda o descanso del molinero ("Muíño de Carral", "Muíño de Redondo", "Muíño de Cagiao", "Muíño de Blanco", "Muíño de Fontechousa", "Muíño de Riocaldo", "Muíño de Barra", "Muíño de Pichin" y "Muíño de Casanova"); cobertizo ("Muíño de Magín", "Muíño do Rato", "Muíño de Portaferreira" y "Muíño de Riocaldo"; pequeño taller ("Muíño de Magín", "Muíño de Daniel"y "Muíño de Riocaldo).

\section{Conclusiones}

Existe una gran variedad en los molinos de este municipio, conservándose actualmente 21 . Uno sigue funcionando todavía como molino, el "Muíño de Fontechousa". Otros, por su estado de conservación, podrían funcionar en la actualidad, como el "Muíño de Redondo"; los hay que aunque se conservan bien, debido a los cambios de uso (bares, almacenes, etc.), necesitarían algunas adaptaciones para volver a funcionar como molino, por ejemplo, el "Muíño de Cagigao". Otros, necesitarían una intervención urgente, o serían necesarios grandes gastos para recuperar su función original (por ejemplo, el "Muíño de Blanco"). Los hay, por fin, que presentan un estado de conservación malo, como el "Muíño de Portaferreira".

La posible reutilización de los molinos presenta un gran interés, pues sería una forma de conservar un patrimonio histórico y mantener el carácter del paisaje regional. Aunque muchos de estos edificios no tengan una historia reconocida, son testigo de la forma de vida que tuvieron nuestros antepasados y que ha moldeado el paisaje durante siglos. También nos permitirá superar las dificultades de la creación de nuevos edificios y su consiguiente impacto paisajístico, al dar prioridad a la recuperación de los antiguos. Entre las posibles reutilizaciones están las instalaciones recreativas (por ejemplo, el Muíño de Cagigao, que está situado en el Club Fluvial de Baamonde), o la reutilización para su aprovechamiento energético(el Muíño de Portaferreira). Debemos remarcar que si queremos conservar los molinos, debemos tener en cuenta que un edificio sin una función está llamado a desaparecer, no tiene valor económico y no será mantenido (Luelmo Varela, E., 1995). Debido al decrecimiento de la población agrícola, debemos aceptar que la mayoría de las construcciones rurales deben tener una nueva función, los cambios funcionales implican una adaptación para este nuevo uso. Esta nueva adaptación exige un conocimiento específico que permita una intervención compatible desde el punto de vista medioambiental.

\section{Agradecimientos}

Los autores quieren expresar su agradecimiento a la Xunta de Galicia, gracias a cuya financiación se hallevado a cabo este trabajo, como parte del proyecto de investigación: "Estimación del impacto visual de las construcciones agrarias en el paisaje rural gallego"(Proy. XUGA 29-102 A94).

\section{BIBLIOGRAFIA}

(1) BAS LÓPEZ, B., 1992: Muíños de marés e de vento en Galicia, Fundación Pedro Barrié de la Maza, A Coruña.

BAS LÓPEZ, B., 1981: Consideracións xerais pró estudo dos muíños en Galicia. Cuadernos de estudios Galegos XXXII.

(3) CONSEJERÍA DE ORDENACIÓN DEL TERRITORIO, MEDIO AMBIENTE Y VIVIENDA. DIRECCIÓN GENERAL DE MEDIO AMBIENTE Y PATRIMONIO ARQUITECTÓNICO: Recuperación de los molinos de Tajuña y su entorno. Comunidad de Madrid.

(4) ESCALERA REYES, J., 1980: Los molinos de agua de la Sierra de Cadiz. Etnografía Española 1. Págs. 267-374. Ministerio deCultura.

(5) GONZÁLEZ, F., PEYRÉGNE, M. y SERRANO, M., 1987: Estudio sobre las pallozas de la Sierra de los Ancares/España. Informes de la Construcción Vol $39, \mathbf{n}^{\circ}$ 392,noviembre/diciembre 1987.

(6) LEMA BENDAÑA, J.R., 1990: Los molinos de San Cristóbal de Cea (Ourense). Arquitectura popular en España. Programa Temático: Antropología Culturaly Social. Consejo Superior de Investigaciones Científicas.

(7) LUELMO VARELA,E., 1995: Restauración de hórreos en el valle de Valdeón (León). Años 1988-1992. Informes dela Construcción, vol 46, n 436, marzo/abril 1995.

(8) PALlARUELO, S.: Los molinos del Alto Aragón Colección de estudios Altoaragoneses. Instituto deestudios Altoaragoneses, Huesca. $310 \mathrm{pp}$.

(9) SAMPEDRO, A, 1990: Tódolos múños da terragallega Colección etnografía galega. Asociación galega para a cultura e a ecoloxía. Vigo.

(10) VENTOSO L., 1996: Múños, memoria de la Galicia industriosa. La voz de Galicia. Suplemento cultura. 4 de enero 1996. 